\title{
Hispanismes
}

Revue de la Société des Hispanistes Français

18 | 2021

Murs, barrières, obstacles dans les mondes hispaniques II

\section{La poésie de Guillermo Carnero}

Un dialogue des cultures pour dépasser les frontières

The poetry of Guillermo Carnero : a dialogue of cultures to go beyond borders

La poesía de Guillermo Carnero: un diálogo de culturas para traspasar fronteras

\section{Catherine Guillaume}

\section{(2) OpenEdition}

12 Journals

\section{Édition électronique}

URL : https://journals.openedition.org/hispanismes/13938

DOI : 10.4000/hispanismes.13938

ISSN : 2270-0765

\section{Éditeur}

Société des Hispanistes Français

Référence électronique

Catherine Guillaume, "La poésie de Guillermo Carnero », HispanismeS [En ligne], 18| 2021, mis en ligne le 31 décembre 2021, consulté le 30 janvier 2022. URL : http://journals.openedition.org/ hispanismes/13938; DOI : https://doi.org/10.4000/hispanismes.13938

Ce document a été généré automatiquement le 30 janvier 2022.

\section{(c) $(9)$}

Les contenus de cette revue sont mis à disposition selon les termes de la Licence Creative Commons Attribution - Pas d'Utilisation Commerciale - Pas de Modification 4.0 International. 


\title{
La poésie de Guillermo Carnero
}

\author{
Un dialogue des cultures pour dépasser les frontières \\ The poetry of Guillermo Carnero : a dialogue of cultures to go beyond borders \\ La poesía de Guillermo Carnero: un diálogo de culturas para traspasar fronteras
}

\section{Catherine Guillaume}

1 En quoi la poésie de Guillermo Carnero, poète et historien espagnol, professeur érudit de littérature espagnole spécialiste du XVIII ${ }^{\mathrm{e}}$ siècle, né à Valence (Espagne) en 1947, peut-elle être lue par le crible de la figure du 'mur', de la 'barrière' ou de l'obstacle' ? Pour explorer ce questionnement, il est important d'envisager l'œuvre dans une double dimension. Tout d'abord celle de sa réception dans l'Espagne des $\mathrm{xx}^{\mathrm{e}}$ et $\mathrm{xxI}^{\mathrm{e}}$ siècles, souvent ralentie par une accumulation de figures de lectures destinées à contribuer davantage à la reconstruction de l'historiographie littéraire de l'Espagne contemporaine qu'à y donner accès. L'instauration de la norme littéraire contribue alors dans une certaine mesure à élever une sorte de barrière entre l'œuvre et son lecteur. Et d'autre part celle des stratégies d'écriture mobilisées par le poète, aussi bien que la géographie référencée et les symboles qui nourrissent sa poésie et relèvent d'une interaction entre le dedans et le dehors, ce qui sous-entend la question du franchissement d'un mur métaphorique, celui que le poète semble ériger entre le poème et son lecteur: une mise à distance paradoxale puisqu'elle permet d'explorer l'altérité entre l'Être et le monde mais s'adresse, comme toute véritable poésie, à l'intime de chaque lecteur. De fait, cette poésie nourrie de culture européenne dont elle opère sans cesse la relecture fissure les représentations du lecteur en même temps qu'elle induit une réflexion sur la création grâce à l'imbrication entre les univers de référence mobilisés par le poète et leur recréation langagière. C'est alors, depuis l'Étranger culturel qui entre en interaction avec la culture propre de chaque lecteur, que se construit une médiation humaniste avec le poète, abattant les murs qui séparent les cultures pour exprimer l'essence d'une complexe relation au monde. 


\section{Une réception critique qui retarde l'accès à l'œuvre}

2 Guillermo Carnero publie en 1967 son premier recueil, le célèbre Dibujo de la muerte, qui érige aussitôt le jeune poète, qui n'a pas encore vingt ans, en emblème des créateurs que l'anthologie de José María Castellet, Nueve novísimos poetas españoles ${ }^{1}$ a contribué à élaborer en tant que figures de la rupture avec les conséquences du procès d'acculturation alors déjà inopérant culturellement, propre au franquisme moribond. Une alternative intellectuelle s'offrait alors aux poètes qui débutèrent leur carrière en termes de publication pendant le 'tardofranquismo' : fallait-il idéologiser ou poétiser? Ce que reprenait le célèbre critique catalan dans la «Conclusión (provisional)» de son ouvrage, grâce auquel fut initiée la réception critique des, dès lors, généralement dénommés 'novísimos' :

Finalmente, todavía unas palabras de Barthes, útiles quizás para la explicación de la aparición del nuevo grupo generacional frente a sus mayores: «...por el momento no hay más que una elección posible y esa elección no puede manifestarse más que sobre métodos igualmente excesivos: o bien proponer una realidad enteramente permeable a la historia, e ideologizar; o bien, por el contrario, proponer una realidad finalmente impenetrable, irreductible y, en este caso, poetizar» ${ }^{2}$.

3 Le choix des 'novísimos' et particulièrement celui de Guillermo Carnero fut alors, comme le comprend tout lecteur de cette œuvre poétique, celui de la poétisation. Celleci, qui comporte à ce jour onze recueils ${ }^{3}$, fissura de fait dès le départ les murs élevés par la dictature au pouvoir en érigeant la culture en tant que possibilité de rompre avec les conséquences de la censure qui avait généré l'apparition de la poésie sociale, la nécessité de faire passer un message politique, parfois crypté, prévalant alors sur la qualité du texte. Deux grands poètes espagnols œuvrèrent dans le milieu des années soixante par leur propre travail créatif et leurs analyses à la remise en question de la poésie espagnole alors en vogue en tant que système oppresseur, soutenant la création des 'novísimos' dès leurs débuts: Jaime Gil de Biedma et José Ángel Valente. La poétisation trouva tout d'abord sa source dans un Ailleurs intellectuel et culturel européen, pour rechercher des nourritures vitales, nécessaires à la fois à la réflexion et à la création :

Nosotros teníamos referentes no españoles, ésta es la cuestión: al menos, los míos. Yo era suscriptor de Tel Quel; [...]...era ir a París a comprar libros que no fueran de Estilística, lo único que entre nosotros había. Si querías otra cosa, leer a Philippe Sollers, a Barthes y demás, tenías que tener tus referentes fuera ${ }^{4}$.

4 Mais cet Ailleurs, ce fut également la Tradition littéraire et artistique, qui ne constitua pas un obstacle à l'écriture poétique mais bien au contraire en devint (et en demeure) le substrat. Il ne s'agit en effet pas de considérer seulement la poésie de Guillermo Carnero (et d'autres 'novísimos') comme l'illustration d'une rupture avec la poésie sociale, une fréquente figure de réception critique, mais de rappeler que pour ces jeunes poètes des années 1970 la culture fut l'outil principal de la rénovation poétique qu'ils menèrent à bien, comme l'explicitait J. Siles, dans un célèbre essai :

Dicha generación -integrada por poetas nacidos entre 1939 y 1953-54- reaccionó, se dice, contra la esclerotizada retórica conocida en España con el nombre de poesía social. Lo que es cierto sólo a medias: porque los novísimos no reaccionaron contra una poesía que, histórica y lingüísticamente, estaba ya muerta, sino contra la noción dominante de un discurso que, desde 1939 y salvo muy pocas excepciones, apenas -pensaban- había experimentado variación. Los novísimos lo que hicieron fue sustituir los rasgos distintivos de ese discurso, que creían cerrado, por otro 
entonces aún sin definir y que, en el primer momento, se caracterizaba, más que por la nulidad de lo buscado, por el denominador común en que se hacía entrar todo cuanto se pretendía rehuir. Lo que tuvo dos efectos casi simultáneos: a) la radicalidad de las posturas, expresa no tanto en los poemas como en las poéticas; $\mathrm{y} b$ ) la asunción de tradiciones varias, reunidas en una sola, que acaso era la misma: la de la tradición como ruptura, la ruptura como tradición ${ }^{5}$.

Il faut souligner que la poésie de Guillermo Carnero se vit en quelque sorte, dès les prémisses de sa réception puis dans les années qui suivirent, ensevelie sous le mur de "l'obstruction référentielle", sous une "chape d'immobilisme critique " ${ }^{6}$, les ouvertures les plus dynamiques venant de l'étranger européen principalement, de l'autre côté du mur (de la frontière) : il fallait en effet à toute force inclure cette poésie dans la norme canonique en reconstruction d'une Espagne renouant avec sa dynamique culturelle et donc critique, qui, n'en retenant que les aspects susceptibles de légitimer son inscription dans la Tradition littéraire espagnole et européenne tels que le culturalisme, la métapoésie ou encore le postmodernisme, laissa le plus souvent de côté la dynamique de médiation que ce poète tisse avec son lecteur. Cette réception dissimule de fait l'œuvre " sous les variantes d'un métarécit critique $»^{7}$ et repose sur un paradoxe: pourquoi la poésie de Guillermo Carnero, omniprésente dans le collectif critique sur les 'novísimos', fait-elle si peu l'objet d'une critique signifiante, empêchant le poète de trouver son lecteur ?8

6 Cet immobilisme critique consiste en effet, "de 1970, date de la parution de l'anthologie de J. M. Castellet, à 2016, date à laquelle est publiée celle d'A. Iravedra ${ }^{9}$, [en un] empilement [de] figures imposées de lecture du référent culturel [qui] s'accroît sans pour autant proposer un regard neuf sur l'œuvre du poète $»^{10}$. Une glose référentielle répétitive, principalement lisible dans les prologues des nombreuses anthologies par lesquelles est médiatisée en Espagne la poésie de l'auteur, qui s'élabore de fait principalement par la recherche dans l'œuvre des traces du culturalisme, du cosmopolitisme et de la métapoésie, avec pour conséquence un balisage de circuits de lecture imposés qui opèrent un conditionnement critique du lecteur. Mais le canal anthologique étant la principale source de publication de la poésie dans l'Espagne de la seconde moitié $\mathrm{du} \mathrm{xx}^{\mathrm{e}}$ siècle et encore à présent, il est difficile d'échapper à ce conditionnement.

7 Et même si Guillermo Carnero a poursuivi son cheminement réflexif et créatif, qui n'a pas seulement consisté à rompre avec la poésie sociale ${ }^{11}$ et qu'il se montre peu ou pas concerné par la réception critique générationnelle des 'novísimos' ${ }^{12}$, l'anthologie de 2016 qui référence sa poésie va comme d'autres ignorer cette évolution et reproduire la rhétorique initiée par J. M. Castellet. La réception de l'œuvre du poète reste figée sur l'instantané d'un renouveau littéraire collectif, qu'elle peine à dépasser. De fait, A. Iravedra souligne, pour construire et légitimer son récit critique, que la réception collective à partir des caractéristiques attribuées aux 'novísimos' dans l'anthologie fondatrice Nueve novísimos (principalement l'apport de nouveautés dans le panorama de la poésie espagnole d'alors, comme "una oleada de aire puro ${ }^{13}$ ) reste d'actualité au sein de la critique lorsqu'elle affirme :

[E]xiste un razonable consenso crítico en que en los primeros años setenta todavía se sostiene una relativa coherencia grupal entre quienes han participado en el primer movimiento novísimo, y el rechazo de la inmediata tradición, la absorción de referentes y modelos marginales, la fusión de preciosismo, surrealismo o irracionalismo simbolista y culturalismo denotado son rasgos que todavía prevalecen ${ }^{14}$. 

l'historiographie littéraire: leurs titres et prologues, répétitifs, font obstacle à un regard neuf ${ }^{15}$, celui que chaque poète 'novísimo' appelle de ses vœux chez son lecteur. Une construction visible également dans la réitération des mêmes choix de poèmes (à quelques variations près) ce qui a pour conséquence un contrôle implicite sur chaque lecteur d'anthologie ${ }^{16}$.

Préalablement à sa découverte du poème le lecteur intéressé prendra ainsi connaissance du traitement accordé au culturalisme ${ }^{17}$, le sujet traité sans exception et dans tout type de discours critique de réception de la poésie de Guillermo Carnero et des 'novísimos'. La critique ne définit pas cette figure imposée de lecture mais l'emplit d'un contenu destiné à définir le champ référentiel de la culture 'novísima' : la culture pour les 'novísimos' serait donc avant tout le culturalisme. Celui-ci n'est pas analysé dans son fonctionnement au sein du poème mais présenté en tant qu'appétence de lecture des 'novísimos' ${ }^{18}$, eux-mêmes envisagés comme un collectif de lecteurs érudits et passionnés : une convocation de la culture comme facteur de rénovation du discours poétique dans l'Espagne des dernières années du franquisme et un "polyfacétisme » cosmopolite en tant que parangon de la rupture avec la poésie sociale. Des éléments exacts pour certains d'entre eux mais qui ne donnent pas pour autant accès au poème, la compréhension du culturalisme au sein de celui-ci ne pouvant se limiter à l'énonciation des sources des lectures du poète Guillermo Carnero au détriment du dialogue qu'il entretient avec la Tradition. En outre, le lecteur contemporain, pour saisir tout le potentiel rénovateur et innovateur du culturalisme, devra également se remémorer l'arrière-plan du contexte d'écriture des premiers poèmes de l'auteur car, relativement accepté et compris au Xxi ${ }^{\mathrm{e}}$ siècle, il n'a pas toujours connu cette bonne fortune critique et chez les lecteurs lorsqu'il s'est agi d'ébranler la norme canonique, ce que rappelle le poète :

El llamado culturalismo está hoy asumido, pero hace cuarenta años era un reto radical a las expectativas de los escritores y lectores de poesía, expectativas que en términos generales, y con excepciones de las que soy consciente y sobre las que he escrito, podrían resumirse en dos elementos. Realismo social e intimismo confesional ${ }^{19}$.

D'autre part, l'importante question de la «máscara cultural " parcourt les écrits critiques, là encore en s'attachant au repérage de celle-ci dans l'œuvre du poète, en relation avec la Tradition, mais, comme dans le cas du culturalisme, sans pour autant en réaliser l'analyse de son fonctionnement dans le poème. C'est ainsi qu'est évoqué le corrélat objectif en tant qu'issu de la poésie de T. S. Eliot, Ezra Pound, V. Aleixandre ou encore L. Cernuda, l'introducteur dans la littérature espagnole de ce procès créatif ${ }^{20}$. Il est également lu en tant que manifestation de la postmodernité dans le poème, comme souvent dans les analyses d'A. P. Debicki ${ }^{21}$ : la poésie de Guillermo Carnero participe ainsi de ce mouvement qualifié de postmoderne, une caractéristique généralement attribuée aux 'novísimos'. L'expression de la dissolution de la voix poématique dans le poème, l'un des importants constituants de l'œuvre du poète, rend en effet manifeste la crise du sujet, autre trait de la postmodernité. Elle donne de plus lieu à l'émergence de la polyphonie textuelle ou intertextuelle, également lue en tant que trace de postmodernité dans cette poésie, comme l'est d'une façon générale ce qui relève de l'indétermination et du scepticisme du poète envers la capacité du langage à rendre compte de la réalité. Dans la même veine, la réflexion du poète sur sa difficulté à trouver sa place en tant qu'artiste dans le monde, un autre axe prégnant de sa poésie, 
est aussi lue par la glose canonique non en tant qu'élément de sa cosmogonie, fonctionnant notamment dans un rapport dialogique avec le référent culturel, mais comme un autre symptôme du postmoderne ${ }^{22}$. Enfin, la critique institutionnelle s'attache généralement à énumérer les outils textuels et langagiers auxquels le poète a recours en tant qu'alternatives à l'expression de l'intimisme primaire : corrélat objectif, monologue dramatique ou utilisation de l'ironie en tant que stratégie de mise à distance des émotions.

11 De plus, cette réception codifiée de l'œuvre du poète se voit renforcée par la considération critique de la métapoésie, omniprésente dans la création de Guillermo Carnero en tant que réflexion au sein du poème sur l'acte d'écriture en lui-même. Elle est le plus souvent présentée dans les différentes médiations critiques comme un maillon de plus de la Tradition littéraire occidentale, ce qu'elle est bien entendu, mais ce qui n'arme pas le lecteur pour la comprendre dans le poème pas plus que son articulation avec l'expression de l'émotion indispensable à l'intensité poétique. En réalité, l'approche critique qui fonde les gloses ultérieures est l'introduction à la première édition des œuvres complètes de Guillermo Carnero, Ensayo de una teoría de la visión ${ }^{23}$, par le poète Carlos Bousoño : ce texte a contribué à donner une assise théorique à cette question dans l'Espagne des années 80 du siècle dernier. Elle constitue une figure de lecture reprise sans exception dans la glose référentielle espagnole sur l'œuvre du poète: celle de la considération de la métapoésie comme outil de lutte sociale contre le langage du pouvoir. De là à conclure que la poésie de Guillermo Carnero est un monde clos, refermé sur lui-même en une tautologie qui met à distance toute émotion, le pas est vite franchi par une critique qui, réalisant une lecture trop sociale (et trop rapide) de cette question, taxera de froide et élitiste la poésie de l'auteur.

12 Ces considérations sur la métapoésie conduisent en outre au débat souvent présent dans la critique sur la notion d'ecphrasis. Dans quelle mesure la poésie de Guillermo Carnero, qui fait tant appel au référent culturel, consiste-t-elle à imiter la réalité ? Un débat qui n'a pas lieu d'être, comme le poète en personne l'a rappelé à maintes reprises ${ }^{24}$.

13 La glose référentielle canonique espagnole, constitue donc, dans le cas de l'accès à la poésie de Guillermo Carnero, une forme d'obstruction, de mur qui s'interpose entre le lecteur et le poème. Même si de fait l'anthologie ou l'essai critique permettent la médiatisation de l'œuvre du poète, ils constituent également en partie un itinéraire de lecture imposé par un autre depuis l'historiographie officielle. Or, le dialogue du lecteur avec l'œuvre ne peut exister que dans la liberté pleine et entière de celui-ci et ne peut se satisfaire de cette approche qui immobilise son regard, empêchant qu'émerge une nouvelle lecture.

14 Cependant le poète, quant à lui, met en jeu des 'murs' et 'barrières', des 'obstacles' langagiers et métaphoriques qui constituent des voiles entre le poème et son lecteur, qu'il s'attache à éveiller, presque à éduquer pourrait-on dire. Mais ces voiles obstructifs sont ici des stratégies d'expression distanciées du Moi poématique et une caractéristique profonde de l'œuvre, qui encore à ce jour, éclaire au travers de ses pudiques dissimulations volontaires les questionnements d'un locuteur poématique en errance au sein de ses géographies référencées. Il est donc nécessaire de dépasser l'événement lyrique des années $70 \mathrm{du}$ siècle dernier pour accéder alors à la signifiance de cette œuvre riche et complexe. 


\section{Fissurer les murs : lire enfin le poème} le principal fondement de sa poésie, la poésie comme "autosalvación $»^{25}$, telle que la définissait le poète espagnol Jaime Gil de Biedma, l'un des maîtres à poétiser du jeune Guillermo Carnero, et l'expression d'un Moi poématique rendu par essence « secondaire " grâce aux stratégies utilisées. D'autre part, c'est également un jeu avec le lecteur qui s'engage à chaque fois ${ }^{26}$ : le poète, qui ne donne jamais à lire un sens univoque et figé forme le vœu d'un lecteur actif, engagé et disponible à la réception de la parole poétique, qu'il va guider et égarer tout à la fois, poursuivant ses itinérances et militant à sa manière pour le dialogue des cultures. Incitant de fait ce dernier à la (re)découverte de la Tradition artistique et littéraire européenne, le poète 'novísimo', qui attend de son lecteur " deseable $»^{27}$ un engagement actif, le guide néanmoins sur les chemins de l'intertextualité, citant ses sources et commentant son œuvre dans ses deux ouvrages autocritiques, Poéticas y entrevistas (2008) et Una máscara veneciana (2014).

Les stratégies de distanciation, qui sont la partie la plus apparente de l'œuvre, ne sauraient cependant dissimuler le questionnement ontologique du poète, celui de la recherche de sa place dans le monde, mais concourent cependant à en voiler la formulation dans le poème, ce qui participe de la dialectique du désir qui permet la mise en place du procès de médiation entre l'auteur et le lecteur. Le lecteur de l'œuvre poétique de Guillermo Carnero devra donc d'emblée faire face à une troublante étrangeté et se laisser (em)porter dans ce jeu ambigu : relative à l'expression du plus profond de soi, cette poésie 'dira' le poète sans cependant jamais le 'raconter', la diction de l'intime étant assurée par le référent culturel, c'est-à-dire par un Ailleurs, dont le poète met en scène la relation qu'il entretient avec lui, à chaque fois renouvelée dans la nouveauté de l'expression langagière du ressenti. Le poème est ainsi envisagé dans son aspect phénoménologique, c'est-à-dire "inséparable de la conscience à laquelle il apparaît et de l'horizon qu'il ouvre $\aleph^{28}$ et non en tant que simple objet d'étude figé qui serait le réceptacle d'une lecture univoque : il est donc à part entière une expérience d'écriture et de lecture, à la fois réponse du poète à la sollicitation du monde et mouvement qui fonde la médiation humaniste avec le lecteur.

À ce titre, la " máscara cultural » est le principal outil du poète pour dépasser les deux caractéristiques majeures de la poésie des années 50 en Espagne (avec de très nombreuses et notables exceptions bien entendu) : l'intimisme primaire et le réalisme social. Ce masque, cher à l'auteur, est à la fois une manière de dire le 'je poématique' grâce à la substitution analogique d'un personnage, voire d'un symbole, comme par exemple le jardin, et une mise en circulation des cultures, rompant ainsi toute 'barrière' entre les aires de création. Il s'incarne tout aussi bien dans les intitulations, dans le recours aux nombreux paratextes placés en tête des recueils ou des poèmes que dans le corps des poèmes eux-mêmes, qui mêlent en des miniatures colorées et vivantes les époques et les lieux, réels ou artistiques, l'auteur n'établissant pas de frontière entre ces deux champs. La richesse interculturelle de la poésie de Guillermo Carnero dit le dedans (l'intime) depuis le dehors (la littérature et les beaux-arts européens) et trouve son pendant dans cette relation dialogique qu'instaure le poète avec son lecteur ou/et son traducteur ${ }^{29}$.

HispanismeS, 18 | 2021 

frappé par l'importance donnée d'emblée au 'mur', à la muraille dans ses trois premiers poèmes : « Ávila », «Castilla » et «Amanecer en Burgos $»^{30}: c^{\prime}$ est ici que naît le locuteur de cette œuvre. Le mur est un obstacle à franchir ${ }^{31}$ tout autant que le point de départ d'une poétique encore vivante aujourd'hui : le premier d'entre eux, "Ávila ", met en scène un locuteur poématique en contemplation devant la statue du prince don Juan dans le couvent de Santo Tomás à Avila - espaces et murs emboîtés -, incarnation de la matrice de cette poésie; le second explore, à travers la proposition d'une lecture/ relecture de l'espace castillan colorée par son paratexte issu du Quichotte, la dimension métapoétique de cette création - le langage est une muraille (No sé hasta cuándo cayera el más lejano cuerpo de muralla ${ }^{32}$ - et le troisième, qui reprend le premier en une circularité elle-même facteur d'enfermement, une image récurrente dans la poésie de l'auteur, met une nouvelle fois en exergue l'immobilité mortuaire du mur qui clôt l'espace, ici précisément le musée de Las Huelgas reales, celui des vêtements sortis des tombes des rois catholiques, images de beauté, refuge dans le monde de l'art, espace parfois clos qui isole du monde, - vouer sa vie à l'art c'est aussi se retirer du monde pour en éviter les souffrances ${ }^{33}$. Dans ces trois poèmes nous voyons donc se forger une poétique propice à rénover la poésie espagnole alors en vogue, grâce à l'importance accordée au référent culturel, à la présence d'un insaisissable locuteur poématique et à la tentation du refuge dans un monde hors du monde, l'ensemble étant placé sous le sceau de l'émotion, facteur d'intensité poétique.

19 C'est justement la question du rapport du poète à l'expression de l'émotion, souvent réduite par la critique à sa fonction de masque de l'intimisme primaire ${ }^{34}$, que le lecteur est invité à explorer en empruntant d'autres voies car il ne s'agit que de voiler l'émotion et non de la faire disparaître, ce qui ôterait tout potentiel d'intensité au poème. Ces voiles prennent ici différentes formes qu'il est possible de considérer comme des avatars, des métamorphoses intimes voulues par le poète qui crée ainsi un espace entre lui et l'émotion, sorte de "gran territorio inexplorado $»^{35}$, pour y faire surgir le langage du poème. Ce recours au voile, qui masque à peine l'émotion affleurante, peut également être lu en tant que tension entre le national et l'étranger : la poésie de Guillermo Carnero existe en effet également dans ce refus de borner la circulation des référents aux frontières géographiques, et le poète, qui en opère la relecture, transforme d'immobiles images en transferts culturels signifiants.

Les intitulations consistent déjà en un jeu entre le poète et le lecteur, car leur immobilité, qui suggérerait à tort une attente en termes d'ecphrasis, oriente déjà bien au contraire vers la recherche ontologique sur la condition humaine, comme le souligne le poète: «cuando adopto para un poema el título de una obra de arte, no estoy describiéndola. [...] Me siento descrito por ella $»^{36}$. Peu abordées dans les écrits secondaires sur l'œuvre du poète si ce n'est dans un essai de F. Brines ${ }^{37}$, elles sont cependant propices à la réception de l'interculturalité convoquée par l'auteur. Les considérer donc comme de simples objets référentiels serait sans nul doute réducteur, car cela reviendrait à figer la réception de cette œuvre dynamique en assimilant le référent culturel à un décor inerte.

21 Si nous observons plus en détail les titres des recueils qui composent l'œuvre, il est possible de noter qu'aucun de leurs intitulés ne comporte de verbe ni d'article défini : le poète choisit des images et laisse au lecteur le soin de leur donner vie dans le procès de médiation qui va s'établir grâce à leur réception puis lors de la lecture du poème. 
D'ailleurs, les choix opérés par les compléments du nom ou l'adjectivation sont on ne peut plus éclairants sur les univers de référence du poète et ses thématiques de prédilection, qui apparaissent ici clairement, comme la mort, le néoplatonisme, la France, le XVIII ${ }^{\mathrm{e}}$ siècle, Paris et Rome, l'Italie, l'Angleterre, la mystique, le surréalisme...

Et de plus, le culturalisme du poète, dont celui-ci donne une analyse complète dans un essai publié en $2000^{38}$, permet de voir que ces titres peuvent parfois être trompeurs et engager le lecteur sur une fausse piste comme dans le cas du poème «El embarco para Cyterea $»^{39}$, référé au célèbre tableau L'Embarquement pour Cythère de Watteau, qui n'a d'ailleurs pas été donné par l'artiste et qui donc, fictif, « va de surcroît à l'encontre des intentions du peintre puisque celui-ci peint en fait un Pèlerinage à l'île de Cythère $»^{40}$, erreur que Guillermo Carnero reprend à son compte, allant jusqu'à utiliser le néologisme Cyterea en lieu et place de l'orthographe espagnole, de façon à mettre volontairement en avant « unas connotaciones arcaicas y relativas a la literatura de fines del siglo XIX, que pretendí mantener y hacer visibles $»^{41}$ et dans le même temps faire siennes les réflexions du peintre :

El hecho de que el poema tome prestado como título el del óleo indica que se trata de un intento de indagación en las reflexiones del pintor al realizarlo, y que el yo del autor las hace suyas después de suponerlas y exponerlas ${ }^{42}$.

L'imaginaire culturel est donc, dès le titre du poème, propice à installer une distance entre le poème et le lecteur.

Nous prendrons également pour exemple le titre du recueil Dibujo de la muerte, de façon à mettre en évidence sa complexité sous-jacente, ce qui constitue déjà un premier défi pour le lecteur en même temps qu'une subreptice et ambivalente invite à entrer dans l'œuvre : de fait, ce titre situe d'emblée la réception du recueil dans un procès de distanciation - «dibujo »-, en même temps qu'il renvoie au monde de l'art et à la finitude de toutes choses - «muerte »-. En effet, l'importance du substantif « dessin » - «dibujo »-, à la fois espace clos et possible représentation ou reflet d'une réalité, rend compte de la relation intellectuelle et émotionnelle complexe qu'entretient le poète avec celle-ci, qu'il ne décrit jamais, mais à partir de laquelle il s'émeut et réfléchit dans son œuvre. Le poète affirme d'ailleurs que « cre[e] que en Dibujo de la muerte hay confesionalidad, porque es un libro escrito desde la elaboración inconsciente de [sus] experiencias reales, sólo que filtradas a través de una cultura y una manera de concebir el poema $»^{43}$.

Le lecteur attentif pourra également découvrir une similaire complexité à l'œuvre dans les titres des poèmes. Prenons pour exemple celui du premier de l'œuvre, "Ávila ", composé d'un unique nom propre, un procédé fréquemment utilisé par l'auteur, ce qui suscite la curiosité du lecteur et induit déjà une médiation interculturelle propre à faire tomber les barrières entre les cultures : en effet ce lecteur, qui n'est pas neutre puisqu'il entre dans l'acte de lire fort de ses propres représentations et de son horizon d'attente, cherchera à établir une relation entre le titre et les contenus du poème, et prendra la mesure de la relecture des référents exécutée par le poète: ici, l'ancrage castillan, parfois utilisé précédemment par la rhétorique franquiste, devenue largement inactive dans l'Espagne des années soixante ${ }^{44}$, est cependant de fait imbriqué dans une approche européenne puisque c'est le sculpteur italien Fancelli qui réalisa en 1512 la tombe du Prince don Juan, devant laquelle locuteur et lecteur naissent à cette poésie dans le même temps que se mettent en place en place les fondements de l'œuvre 
(interculturalité, métapoésie, méditation sur l'humain) : un dynamitage des murs entre les cultures par le transfert culturel, une constante dans l'œuvre du poète.

De plus, dans la poésie de Guillermo Carnero, le seuil intitulatif du poème est très souvent complexifié par le recours au paratexte ou à l'épigraphe, articulé à l'évocation d'un référent culturel, de façon à en désautomatiser la réception. Nous prendrons comme exemple les deux paratextes inauguraux du recueil initial Dibujo de la muerte en tant que parangons du fonctionnement paratextuel au sein de l'œuvre globale. Ils peuvent de plus être relus a postériori en tant qu'inauguraux de toute l'œuvre poétique, même si telle n'était pas l'intention première puisqu'ils le sont en réalité du seul recueil Dibujo de la muerte. Ils posent en effet les éléments structurants et portent déjà l'ambivalence constituante de la création de l'auteur.

Observons-les attentivement :

Vobiscum cupiam quolibet esse modo.

Ovidio, Tristes, V, I

puis, juste après,

Ne voise au bal qui n'aimera la danse.

Guy du Faur de Pibrac ${ }^{45}$

La complexité référentielle dont est coutumier le poète apparaît déjà ici de façon évidente : pour les sources, Ovide, la poésie latine donc, premier référent culturel et propos introductif de l'œuvre. En l'occurrence ici, la poésie de l'exil. Le recueil Tristes appartient en effet à cette période créative du poète latin, qui plus est dans la forme mélancolique de l'élégie, le vers retenu étant le dernier de l'élégie I du livre V ; puis, dans la seconde de ces épigraphes, de nouveau la poésie, mais du xvI siècle français, ce qui met en avant la géographie référencée de l'auteur, le $\mathrm{xvI}$ siècle artistique européen étant une fréquente période de référence dans son œuvre. Une complexité paradoxale se met ici en marche, qui distancie déjà le lecteur tout en convoquant son concours, tandis que la réception de l'œuvre se teinte d'une émotion mélancolique : en effet, Ovide, dans cette sombre élégie, s'adresse depuis l'exil à un lecteur lointain. Elle se termine par le vers choisi par le poète espagnol pour, au contraire, ouvrir le recueil Dibujo de la muerte: "Voulez-vous savoir pourquoi je vous envoie mes ouvrages? C'est que, de quelque manière que ce soit, je veux être [...] avec vous $»^{46}$. Ce choix épigraphique souligne donc bien que la poésie de Guillermo Carnero s'adresse, par analogie, à un lecteur actuel, présenté comme la première composante de l'œuvre, mais que c'est aussi l'expression de l'intime distancié grâce au référent artistique qui est ici en jeu. De fait, l'importance du lecteur « deseable » est bien palpable dès l'entame de l'œuvre : en effet, la seconde épigraphe confirme cette recherche d'un alter ego lecteur, averti cependant en bonne et due forme par le poète : sa tâche sera rude et nécessitera un engagement opiniâtre. De plus, lorsque grâce à cette épigraphe, le poète s'adresse au lecteur par la voix d'un danseur, le procès de transduction intersémiotique ${ }^{47}$ auquel il aura souvent recours est déjà opérant. Voici donc mis au jour, en deux paratextes, les axes structurants de l'œuvre: une volonté de partage d'un intime douloureux avec un lecteur "deseable", accueilli en même temps que mis à distance, dans une "altérité structurante $\aleph^{48}$ qui s'ancre dans la paradoxale convocation des référents culturels, « une transcendance muette $\mathrm{du}$ " tu» au cœur de la saisie de soi $»^{49}$ qui culmine dans l'amer constat de l'impossibilité de l'art à constituer une échappatoire à la répétitive banalité du monde. 
, il est également fondamental, pour entrer dans cette œuvre majeure, de prendre en considération la problématique du double en tant qu'autre voile mis sur la route du lecteur dans son accès au poème. C'est ainsi qu'au fil des années et des recueils Guillermo Carnero va donner à voir, par référents interposés, l'ordonnancement scénique de son rapport au monde: "spectateur du monde", le poète cherche néanmoins à « s'examiner soi-même $\|^{50}$ en donnant corps à cette dualité, objectivée et distanciée par la mobilisation de ses différents avatars. Littéraires, picturaux, architecturaux, paysagers, objectaux, les référents avec lesquels le poète construit sa relation dialogique à l'Europe de la culture, qui configurent en quelque sorte la «[g]alería de retratos ${ }^{51}$ de ses compagnons de route créatifs et réflexifs, se démultiplient également dans une pluralité de figures langagières qui ordonnent son propre insaisissable dans le miroir de l'altérité. Ce fécond procès de décentrement met en lumière l'ambivalence du poète, partagé entre le désir du refuge dans l'Art, une thématique au long cours présente dès le début de l'œuvre et jusque dans Carta florentina ${ }^{52}$, et celui de la construction de Soi à travers l'Autre. La lecture des recueils expose donc le lecteur à la réception de cette cohorte d'influences constituée de peintres, poètes, écrivains, sculpteurs, musiciens, philosophes... auxquels le poète à sa façon rend hommage tout en les fictionnalisant. Ils participent pleinement du dialogue entre les cultures, mis aussi en avant en tant stratégie de résistance au délitement de la culture européenne de la fin du Xx et du début du Xxi ${ }^{e}$ siècle.

Pour conclure notre propos, nous rappellerons qu'une double dynamique est à l'œuvre lorsqu'il s'agit de devenir lecteur de la poésie de Guillermo Carnero. D'une part, la prise en compte de la nécessité contextuelle de la reconstruction du canon après les années d'acculturation franquiste, qui perdure au fil des années et produit une critique d'ordre institutionnel, principalement repérable dans les anthologies qui publient la poésie de l'auteur, et ralentissant l'accès à cette œuvre. Et d'autre part, une dynamique culturelle et interculturelle bien perceptible par tout lecteur qui aborde la complexité de son maillage interculturel. C'est que, dans cette poésie à sa façon militante, l'immobilité du refus de l'altérité par une relation à sens unique au référent culturel (mimesis) n'est pas tenable et que l'échange interculturel nourricier et en mouvement propre à faire tomber les murs et les barrières entre les cultures se fait également indispensable voie de découverte de Soi, effaçant les obstacles à la naissance d'une altérité féconde grâce à ce dialogue entre les cultures et avec le lecteur.

\section{BIBLIOGRAPHIE}

Jacques ANCET, Neuf poètes espagnols $d u X^{e}$ siècle, Bordeaux, Plein Chant, cahiers poétiques, littéraires et champêtres, $n^{\circ} 25$ (hiver 1975).

Roland BARTHES, Le plaisir du texte, Seuil, Paris, 1973.

Jean-Paul BOUILLON, « TITRE DES EUUVRES D'ART », Encyclopedia Universalis [on-line], [consulté le 11 mars 2018] <URL : http://www.universalis.ft/encyclopedie/titre-des-œuvres-d-art/>.

HispanismeS, $18 \mid 2021$ 
Francisco BRINES, « Integración del título en el poema », Ínsula n 310 (septiembre 1972), p. 4,7.

Guillermo CARNERo, Ensayo de una teoría de la visión, Madrid, Hiperión, 1979. [2éd. 1983]. Prologue de Carlos Bousoño.

Guillermo CARNERo, Dibujo de la muerte. Obra poética, Ignacio Javier López (éd.), Madrid, Cátedra, col. Letras Hispánicas 444, 1998 ; $2^{\mathrm{e}}$ éd., col. Letras Hispánicas 485, 2010. (Comprend les recueils Dibujo de la muerte, El sueño de Escipión, Variaciones y figuras sobre un tema de La Bruyère, El azar objetivo, les trois poèmes de « Ensayo de una teoría de la visión », les quatre du « Ciclo de Dibujo de la muerte » et Divisibilidad indefinida).

Guillermo CARNERo, Verano inglés, Barcelona, Tusquets, col. Nuevos Textos Sagrados 180, 1999 [2 ${ }^{\mathrm{e}}$ éd., 2000].

Guillermo CARnERo, Espejo de gran niebla, Barcelona, Tusquets, col. Nuevos Textos Sagrados 207, 2002.

Guillermo CARnero, Fuente de Médicis, Madrid, Visor, col. Visor de Poesía 609, 2006.

Guillermo CARNERo, Poéticas y entrevistas (1970-2007), Málaga, Centro Cultural de la Generación del 27, col. Estudios del 27, 15, 2008.

Guillermo CARNERo, Cuatro Noches Romanas, Barcelona, Tusquets, col. Nuevos Textos Sagrados 254, 2009.

Guillermo CARNERO, El poeta subterráneo o mis tres criptomanifiestos, Salamanca, publicaciones del Semyr, 2010.

Guillermo CARNERo, « Por signos de letrado: imaginario cultural y autoanotación », VV.AA. Crítica genética y edición de manuscritos hispánicos contemporáneos, Salamanca, Universidad, 2012, p. 23-31. Guillermo CARNERo, Una máscara veneciana, Valencia, Institución Alfonso el Magnánimo, col. Debats 29, 2014.

Guillermo CARNERO, Regiones devastadas, Sevilla, Fundación José Manuel Lara, Vandalia, 2017.

Guillermo CARNERO, « Muchos lectores no quieren conocer, quieren reconocer » [on-line], elcultural.es (05/04/2017) [consulté le 15/12/2021] <URL: https://elcultural.com/GuillermoCarnero-Muchos-lectores-no-quieren-conocer-quieren-reconocer>.

Guillermo CARNERo, Carta florentina, Sevilla, Fundación José Manuel Lara, Vandalia, 2018.

Guillermo CARNERO, « Mayo del 68: París y Barcelona » [on-line], RDL, Revista de Libros, Segunda época (16/05/2018) [consulté le 15/12/2021] <URL: https://www.revistadelibros.com/articulos/ mayo-del-68-paris-y-barcelona>.

Guillermo CARNERO (entrevista con Juan Lagardera), « Guillermo Carnero, 'Tengo la convicción de pertenecer a una época pasada y mejor' » [on-line], Levante, El mercantil valenciano, Posdata (12/05/2018) [consulté le 15/12/2021] <URL:https://www.levante-emv.com/postdata/ 2018/05/11/guillermo-carnero-conviccion-pertenecer-epoca11975401.html>.

Guillermo CARNERO, « Barcelona en tiempos de los novísimos, y hoy (1968-2018) », Cuadernos hispanoamericanos, $\mathrm{n}^{\circ} 823$ (enero 1, 2019), p. 104-113.

Guillermo CARNERo, Jardín concluso. (Obra poética 1999-2009), Elide Pittarello (éd.), Madrid, Cátedra, col. Letras Hispánicas 830, 2020. (Comprend la réédition des recueils Verano inglés, Espejo de gran niebla, Fuente de Médicis, Cuatro noches romanas). 
José María CASTELLET, Nueve novísimos poetas españoles, Barcelona, Península, 2010 [ $1^{\text {re édition, }}$ Barcelone, Barral Editores, 1970].

Nicolas CASTIN, Sens et sensible en poésie moderne, Paris, Puf écriture, 1998.

Jean CHEVALIER, Alain GHEERBRANT, Dictionnaire des symboles, Paris, Robert Laffont/Jupiter, coll. Bouquins, 1987.

Michel collot, La poésie moderne et la structure d'horizon, Paris, Puf, édition du Kindle [on-line], 2015.

Trevor J. DADSON, « La reapropiación del lenguaje poético del franquismo: el caso de Dibujo de la muerte de Guillermo Carnero ", Breve esplendor de mal distinta lumbre. Estudios sobre poesía española contemporánea, Sevilla, Renacimiento, col. Iluminaciones 5, 2005, p. 13-104.

Andrew P. DEBICKI, « Poesía española de la posmodernidad », Anales de Literatura Española ${ }^{\circ} 6$ (1988), p. 165-180.

Andrew P. DEBICKI, «La poesía posmoderna de los novísimos: una nueva postura ante la realidad y el arte», Ínsula 505 (enero 1989), p. 15-16.

Andrew P. DEBICKI, « Una poesía de la posmodernidad: los novísimos », Anales de la Literatura Española Contemporánea 14.13 (1989), p. 33-50.

Emmanuel FRAISSE, Les anthologies en France, Paris, L'Harmattan, 2017.

Catherine Guillaume, La poésie de Guillermo Carnero - Lectures en devenir, Paris, L'Harmattan, 2020. (De manière générale, une étude complète de l'historicité de la réception de l'œuvre du poète peut être lue dans cet ouvrage, en réalité la publication de notre thèse, p. 41-137).

Araceli IRAVEDRA, Hacia la democracia, la nueva poesía (1968-2000), Poesía española, antología crítica dirigida por Francisco Rico, Madrid, Visor, Centro para la edición de los clásicos españoles, 2016. Luis MARTÍN ESTUDILLO, La mirada elíptica: el trasfondo barroco de la poesía española contemporánea, Madrid, Visor libros, 97, 2007.

Fulgencio MARTíNEZ, « Conversación con Guillermo Carnero », [Boletín digital 8.], Ágora, Papeles de arte gramático, $\mathrm{n}^{\circ} 23$ (Marzo-abril 2011) [consulté le 15/12/2021] <URL : https://issuu.com/ agoralarevistadeltaller/docs/agora_n__23_boletin_8-2__/1> (Numéro spécial consacré à Cuatro noches romanas).

Elide PITTARello, "El ideal herético de Guillermo Carnero en "Une semaine de bonté" ", Vivir es ver volver: studi in onore di Gabriele Morelli, Bergamo university press, Sestante edizioni, 2009, p. 409-416.

Elide PITTARELlo, « Piazza d'Italia: un poema metafísico de Guillermo Carnero », en Andrea Baldissera, Giuseppe Mazzocchi e Paolo Pintacuda (a cura di), Ogni onda si rinnova. Studi di ispanistica offerti a Giovanni Caravaggi, vol. II, Como-Pavia, Ibis, 2011, p. 511-526.

Jaime SILES, « Los novísimos: la tradición como ruptura, la ruptura como tradición », Ínsula, 505 (enero 1989).

Jénaro TALENS, «La coartada metapoética», Ínsula 512-513 (agosto-septiembre 1989), p. 55-56. Marie-Claire ZIMMERMAnN, Poésie espagnole moderne et contemporaine, Paris, Dunod, 1995. 


\section{NOTES}

1. José María CASTELLET, Nueve novísimos poetas españoles, Barcelona, Península, 2010.

2. Ibid., p. 46-47.

3. V. bibliographie.

4. Fulgencio MARTínEZ, « Conversación con Guillermo Carnero », [Boletín digital 8.], Ágora, Papeles de arte gramático, $\mathrm{n}^{\circ} 23$ (Marzo-abril 2011) <URL: https://issuu.com/agoralarevistadeltaller/ docs/agora_n__23_boletin_8-2__/1>, p. 29.

5. Jaime SILES, « Los novísimos: la tradición como ruptura, la ruptura como tradición », Ínsula, 505 (enero 1989), p. 9.

6. Catherine Guillaume, La poésie de Guillermo Carnero - Lectures en devenir, Paris, L'Harmattan, 2020 , p. $35,15$.

7. Ibid., p. 16 .

8. Un paradoxe que le poète en personne souligne de nouveau en 2020 , dans sa " Nota del autor » à Jardín concluso.

9. Araceli IRAVEDRA, Hacia la democracia, la nueva poesía (1968-2000), Poesía española, antología crítica dirigida por Francisco Rico, Madrid, Visor, Centro para la edición de los clásicos españoles, 2016.

10. Catherine Guillaume, op. cit., p. 35-36.

11. En 2018 encore le poète rappelait que « la generación poética a la que pertene[ce], la llamada "del 68", "del Mayo francés" o "novísima", adoptó la mejor actitud ante el franquismo: ni la éticamente inaceptable de adherirse a él, ni la utópica y estéril de seudocombatirlo, sino la más drástica que existe como rechazo: ignorarlo, claro, sabiendo que su deseable fin estaba próximo, y no dependía de la literatura. [...]. Se ha dicho y repetido que la antología [de Castellet] marcó la emergencia de una generación que pretendía dar la puntilla a la poesía social, lo cual es una simplificación y una inexactitud. Lo primero, porque se trataba de dar una alternativa a la poesía confesional primaria, tanto si la confesión era un mensaje doctrinario como autobiográfico neorromántico. Lo segundo porque la poesía social había fallecido ya, y su defunción había sido certificada por la vanguardia de quienes la habían practicado, proclamando que la coartada ideológica para escribir con torpeza había caducado. Por eso Castellet, Gil de Biedma y Barral nos comprendieron y apoyaron. Si la caricatura que de nosotros han querido hacer algunos tuviera sentido, no habríamos recibido el apoyo de la izquierda, ni la izquierda nos habría promocionado ", Guillermo CARNERO, "Mayo del 68: París y Barcelona ", RDL, Revista de Libros, Segunda época, [on-line] (16 de mayo de 2018) <URL: https://www.revistadelibros.com/ articulos/mayo-del-68-paris-y-barcelona>.

12. Guillermo CARNERo in Fulgencio MARTínEZ, op.cit., p. 29: "Como comentario marginal, no quiero volver a hablar en plural; no tengo derecho a hablar de los otros de mi 'generación', porque no creo que estemos ante una historia compartida ».

13. José María CASTELLET, op. cit., p. 31, en référence à l'importation de nouvelles façons de penser la création littéraire, comme par exemple la sensibilité camp, ce qui a constitué « una oleada de aire puro en nuestro mundo cultural», détruisant «la actitud maniquea de la generación anterior » en tournant le dos à « el epicentro bueno-malo del enjuiciamiento estético habitual ».

14. Araceli IRAVEDRA, op. cit., p. 64.

15. En effet, comme le rappelle Emmanuel FRAISSE, « [1]es anthologies prétendent exprimer la réalité d'une littérature propre au groupe dont elles émanent et contribuer à le constituer en tant que tel. Parce qu'elles ont pour objet de définir les productions les plus caractéristiques ou les plus belles de la collectivité nationale, parce qu'elles sont à la fois preuve tangible de la vitalité séculaire d'une littérature et moyen de renforcer ce groupe en lui donnant des repères et un patrimoine commun ", Les anthologies en France, Paris, L'Harmattan, 2017, p. 131-32.

16. C'est de fait par les poèmes tirés de Dibujo de la muerte, "Ostende ", "El embarco para Cyterea » et "Capricho en Aranjuez » que le lecteur est le plus souvent invité à entrer dans 
l'œuvre du poète, Guillermo CARNERO, Dibujo de la muerte. Obra poética, Ignacio Javier López (ed.), Madrid, Cátedra, col. Letras Hispánicas 444, $1998 ; 2^{\mathrm{e}}$ ed., col. Letras Hispánicas 485, 2010. Toutes nos citations de ce recueil sont issues de la $2^{\mathrm{e}}$ édition (2010).

17. L'hispaniste Elide PITTARELLO rappelle les circonstances, parfois polémiques, qui ont conduit à l'adoption de cette appellation critique : «En la España de Franco, mientras triunfaba la poesía social o comprometida, anclada a las circunstancias históricas y biográficas del momento, el poeta 'novísimo' se volcaba en exquisiteces anacrónicas y ajenas, en su mayoría, a la tradición española: una elección que fue polémicamente tildada de 'culturalista' ", " Piazza d'Italia: un poema metafísico de Guillermo Carnero ", en Andrea Baldissera, Giuseppe Mazzocchi e Paolo Pintacuda (a cura di), Ogni onda si rinnova. Studi di ispanistica offerti a Giovanni Caravaggi, vol. II, Como-Pavia, Ibis, 2011, p. 523.

18. À quelques exceptions près, dont l'une est de taille puisqu'il s'agit du célèbre CASTELLET qui affirme, op. cit., p. 25, que « el grupo generacional al que nos estamos refiriendo es, en España, el primero que se forma íntegramente desde unos supuestos que no son del humanismo literario" », et p. 39 que "donde todos están, probablemente, de acuerdo, es que en su formación cultural la literatura no ha representado más que un porcentaje limitado, muy inferior al que representó para las generaciones anteriores». Jacques ANCET affirme également que "leur rupture [des poètes novísimos] avec l'humanisme littéraire n'est pas de l'ordre de l'opposition systématique mais de l'ignorance ", Neuf poètes espagnols du Xx siècle, Bordeaux, Plein Chant, cahiers poétiques, littéraires et champêtres, $\mathrm{n}^{\circ} 25$ (hiver 1975), p. 24.

19. Guillermo CARNERO, « Por signos de letrado: imaginario cultural y autoanotación », VV.AA. Crítica genética y edición de manuscritos hispánicos contemporáneos, Salamanca, Universidad, 2012, p. 25. Échapper à l'intimisme primaire et dépasser un réalisme social qui avait d'ailleurs déjà vécu lors des dernières années du franquisme sont des caractéristiques qui ont fortement structuré la poésie de Guillermo Carnero et qui demeurent toujours d'actualité. En 1999, le poète écrivait à ce propos, livrant une très importante clé de compréhension de sa poésie: "el intimismo de referente cotidiano puede producir insignificación e insignificancia tanto si se mantiene en el discurso del yo emocional lexicalizado como si se entrega sin reservas al automatismo irracional. Entre ambos extremos queda un amplio territorio de exploración lingüística e ideológica, tan accesible como el que ofrece el imaginario cultural objetivando el yo por analogía ", Poéticas y entrevistas (1970-2007), Málaga, Centro Cultural de la Generación del 27, col. Estudios del 27, 15, 2008, p. 62.

20. Par contre, Guillermo CARNERO, qui inscrit pleinement sa création dans la Tradition littéraire rappelle encore en 2019 l'importance de ce poète dans sa création : « La delegación del Fondo de Cultura Económica de Méjico, donde compré, en 1965 y de forma semiclandestina, la recién aparecida cuarta edición de La realidad y el deseo de Luis Cernuda, que incorporaba su último libro, Desolación de la Quimera, y en él poemas que decidieron mi vocación y mi poética, como 'Luis de Baviera escucha Lohengrin' ", "Barcelona en tiempos de los novísimos, y hoy (1968-2018)", Cuadernos hispanoamericanos, $\mathrm{n}^{\circ} 823$ (enero 1, 2019), p. 3 de la version numérique de l'article remise par l'auteur.

21. Cf. bibliographie.

22. Ce qu'E. PitTarello, « Piazza d'Italia... », op.cit., p. 525, précise comme étant « la búsqueda de un rol para el artista en el desencanto de la postmodernidad ».

23. Madrid, Hiperión, 1979.

24. "Con la distancia y la perspectiva que el tiempo impone, yo diría que una gran diferencia, dentro de la unidad y la coherencia, separa la primera época [de mi obra] de la segunda. En la primera descubrí los puntales de una poética que iba desde entonces, y para siempre, a vertebrar mi pensamiento y mi escritura: cómo la literatura y el arte dan cuenta de mí a través de la realidad y mi experiencia de ella, trascendiéndola más allá de la mímesis y en lucha con el 
lenguaje ». Guillermo CARNERO, Jardín concluso. (Obra poética 1999-2009), Elide Pittarello (éd.), Madrid, Cátedra, col. Letras Hispánicas 830, 2020, p. 239.

25. Jaime Gil DE BIEDMA, cité dans Guillermo CARNERO, «Muchos lectores no quieren conocer, quieren reconocer ", elcultural.es (5/04/2017), p. 2. Le poète y précise (Id.), en réponse à une question sur la publication de Regiones devastadas : «P. En el libro se desgranan sus temas clásicos (memoria, muerte), pero quizá ya desde el título predomina la necesidad de crear arte y sobrevivir en él. ¿Podría verse como un testamento moral? R. Yo le llamo a esto el intento de definir la propia identidad. La poesía sirve para eso. Jaime Gil de Biedma decía que es un proyecto de autosalvación, y creo que se refería a lo mismo. A cómo te reconoces a ti mismo en el poema y el poema te ayuda a definir lo que tú eres; a cómo amplías tu visión del mundo a base de leer y de escribir ».

26. Ce que Roland BARTHES précise ainsi : «Si je lis avec plaisir cette phrase, cette histoire ou ce mot, c'est qu'ils ont été écrits dans le plaisir [...]. Mais le contraire? Écrire dans le plaisir m'assure-t-il - moi, écrivain - du plaisir de mon lecteur ? Nullement. Ce lecteur, il faut que je le cherche [...], sans savoir où il est. Un espace de la jouissance est alors créé. Ce n'est pas la "personne» de l'autre qui m'est nécessaire, c'est l'espace : la possibilité d'une dialectique du désir, d'une imprévision de la jouissance : que les jeux ne soient pas faits, qu'il y ait un jeu. [...] Le texte que vous écrivez doit me donner la preuve qu'il me désire. Cette preuve existe: c'est l'écriture. L'écriture est ceci : la science des jouissances du langage, son kāmasūtra (de cette science, il n'y a qu'un traité : l'écriture elle-même) ", Le plaisir du texte, Paris, Seuil, 1973, p. 86-87. 27. Le poète le définissait ainsi en 2004 : «El lector deseable es un lector activo y sin prejuicios, que acepte la posibilidad de opciones distintas a las suyas, que admita cualquier poética atendiendo sólo a la calidad de los textos ", Poéticas..., op. cit., p. 266. V. aussi Luis MARTín ESTUdillo, La mirada elíptica: el trasfondo barroco de la poesía española contemporánea, Madrid, Visor libros 97, 2007, notamment le chap. 5 : «De la metapoesía a los metadiscursos: hacia la activación del lector ».

28. Michel collot, La poésie moderne et la structure d'horizon, Paris, Puf, édition du Kindle [on-line], 2015, [emplacement du Kindle, 104].

29. Ce rôle du lecteur est aux antipodes de ce que Marie-Claire ZIMMERMANN donne comme caractéristiques du lecteur de poésie sociale: «La poésie dite sociale impliquait une réelle connivence entre un public privé de liberté et un auteur qui tentait de parvenir à dire indirectement ce que la loi de censure lui interdisait d'exprimer clairement. Il fallait à tout prix que le locuteur et le lecteur fussent d'accord sur un signifié. Les grands poètes engagés cherchaient à rétablir la communication perdue entre les Espagnols ; le texte poétique constituait un instrument privilégié pour cela, mais quelle que fût la capacité créatrice d'un Blas de Otero, il est vrai qu'une écriture "sociale » entraînait systématiquement un certain type de décodage ", Poésie espagnole moderne et contemporaine, Paris, Dunod, 1995, p. 157. En cela réside l'une des grandes innovations des novísimos.

30. Dibujo de la muerte, op. cit., respectivement p. 115, 121, 124.

31. "Le mur c'est la communication coupée, avec sa double incidence psychologique : sécurité, étouffement ; défense, mais prison. Le mur rejoint ici la symbolique de l'élément féminin et passif de la matrice ", Dictionnaire des symboles, op. cit., p. 654.

32. Guillermo CARNERO, Dibujo de la muerte, op. cit., p. 121, v. 2.

33. Cette image est également tout à fait prégnante dans le dernier poème de Verano inglés, «Campos de Francia », où le poète rappelle l'importance de ce refuge dans le monde de l'art: « Nunca/hizo tanto por mí ningún ser vivo », Barcelona, Tusquets, col. Nuevos Textos Sagrados 180,1999, p. 69.

34. Luis MARTÍN ESTUDILLO synthétise cette tendance de la critique : «Fue la generación llamada 'novísima' o 'del 68' la que desde mediados de los años sesenta del siglo pasado abogó con más 
ímpetu por una estética que se alejara del protagonismo que el yo había adquirido en las corrientes más visibles de las dos promociones poéticas anteriores, las cuales habían basado su rehumanización del discurso lírico (tras la ruptura estética de las vanguardias y el colapso ocasionado por la guerra) en la exhibición palmaria de un sujeto poemático bien determinado que se enfrentaba a la sordera divina o la injusticia social», La mirada..., op. cit., p. 37-38.

35. Guillermo CARNERo, "Ficción de la palabra », Espejo de gran niebla, Barcelona, Tusquets, col. Nuevos Textos Sagrados 207, 2002, p. 55. À ce propos, l'auteur précisait en 2003 le sens qu'il donne à ce territoire à explorer, en réponse à une question de J. SILES : «P. - ¿Qué es para ti 'el gran territorio inexplorado' que, según el quinto poema [de Espejo de gran niebla], existe 'entre la realidad y su imagen escrita' ? R. -Es el espacio que separa la poesía que me interesa de la que simplemente se propone transcribir anécdotas existenciales nimias o reiterar la psicología barata y los tópicos del sentimentalismo primario». Guillermo CARNERo, Poéticas..., op. cit., p. 272.

36. Guillermo CARNERo, Una máscara veneciana, Valencia, Institución Alfonso el Magnánimo, col. Debats 29, 2014, p. 45. Voir aussi le «Pórtico» de Regiones devastadas, Sevilla, Fundación José Manuel Lara, Vandalia, 2017, p. 11. Le poète y rappelle une nouvelle fois, lorsqu'il évoque les « elementos del imaginario cultural» mobilisés dans ses poèmes que «nunca [se] $\mathrm{h}[\mathrm{a}]$ limitado a describirlos ».

37. Francisco BRINES, «Integración del título en el poema », Ínsula n 310 (septiembre 1972), p. 4,7, sur le poème «El altísimo Juan Sforza compone unos loores a su dama mientras César Borgia marcha sobre Pésaro ».

38. « Culturalismo duro, de baja, intensidad, criptoculturalismo, culturalismo ficticio », Poéticas..., op. cit., p. 67-75.

39. Dibujo..., op. cit., p. 181.

40. Jean-Paul BoUILLON, « TITRE DES CEUVRES D’ART », Encyclopedia Universalis [on-line], [consulté le 11 mars 2018] <URL : http: //www.universalis.ft/encyclopedie/titre-des-œuvres-d-art/>.

41. Guillermo CARNERo, Poéticas..., op. cit., p. 108.

42. Ibid., p. 110.

43. Ibid., p. 171.

44. Trevor J. DADSON précise l'importance donnée selon lui à la Castille par l'idéologie franquista : « Un lazo final con los Reyes Católicos es el énfasis puesto sobre Castilla, y en particular Castilla la Vieja. Ya en 1935 el líder monárquico José Calvo Sotelo había declarado que 'nosotros anhelamos la vuelta a Toledo, Valladolid, Medina [...], la Hispanidad, el Imperio'. Franco estableció su cuartel general durante la guerra civil en Burgos, capital de Castilla la Vieja, desde donde transmitía sus discursos por radio, y ciudad con poderosas y emotivas asociaciones con el pasado: por ejemplo, el Cid Campeador ", «La reapropiación del lenguaje poético del franquismo: el caso de Dibujo de la muerte de Guillermo Carnero ", Breve esplendor de mal distinta lumbre. Estudios sobre poesía española contemporánea, Sevilla, Renacimiento, col. Iluminaciones 5, 2005, p. 18-19.

45. Dibujo..., op. cit., p. 113.

46. Nous traduisons.

47. V. Elide PITTARello, «El ideal herético de Guillermo Carnero en "Une semaine de bonté" ", Vivir es ver volver: studi in onore di Gabriele Morelli, Bergamo university press, Sestante edizioni, 2009, p. 409.

48. Nicolas CASTin, Sens et sensible en poésie moderne, Paris, Puf écriture, 1998, p. 69

49. Id.

50. Id.

51. Dibujo..., op. cit., p. 154.

52. Le poète réaffirmait encore récemment son sentiment de « segregación de la realidad: Tengo la convicción de pertenecer a una época pasada y mejor », "Guillermo Carnero, "Tengo la 
convicción de pertenecer a una época pasada y mejor" ", entrevista con Juan Lagardera, Levante, El mercantil valenciano, Posdata (12/05/2018).

\section{RÉSUMÉS}

L'œuvre poétique de Guillermo Carnero, poète 'novísimo' des $\mathrm{xx}^{\mathrm{e}}$ et $\mathrm{xxI}^{\mathrm{e}}$ siècles, peut être lue par le crible de la figure du 'mur', de la 'barrière' ou de l'obstacle' : de fait, aussi bien les figures de lecture répétitives qui constituent un frein à sa réception que les stratégies d'écriture mobilisées par le poète, sa géographie référencée et les symboles qui la construisent relèvent d'une interaction entre le dedans et le dehors. Cette poésie, nourrie de culture européenne dont elle opère sans cesse la relecture, fissure nos représentations et nous induit à la réflexion sur la création et sur le sens de la vie grâce à l'imbrication des univers de référence mobilisés par le poète, langagièrement recréés. C'est alors, depuis l'Étranger culturel qui entre en interaction avec la culture de chaque lecteur, que se construit une médiation humaniste avec le poète, abattant les murs qui séparent les cultures pour exprimer l'essence d'une complexe relation au monde.

The poetic work of Guillermo Carnero, a 'novísimo' poet of the 20th and 21st centuries, can be read through the sieve of the figure of the 'wall', the 'barrier' or the 'obstacle': in fact, both the repetitive figures of reading that constitute a hindrance to its reception as well as the writing strategies mobilized by the poet, its referenced geography and the symbols that construct it, are the result of an interaction between the inside and the outside. This poetry, nourished by European culture, which it constantly re-reads, cracks our representations and induces us to reflect on creation and on the meaning of our life thanks to the interweaving of the reference universes mobilized by the poet, which are linguistically recreated. It is then, from the cultural stranger who interacts with the culture of each reader, that a humanistic mediation is built between the poet and his reader, breaking down the walls that separate cultures to express the essence of a complex relationship to the world.

\section{INDEX}

Mots-clés : poésie contemporaine espagnole, Guillermo Carnero, novísimos, relation dialogique et interculturelle, médiation humaniste, interculturalité

Keywords : Spanish contemporary poetry, Guillermo Carnero, novísimos, dialogical and intercultural relationship, humanist mediation, interculturality

\section{AUTEUR}

\section{CATHERINE GUILLAUME}

Université d'Orléans 